\title{
What is the best indication for single-incision Ophira Mini Sling? Insights from a 2-year follow-up international multicentric study
}

\author{
Paulo Palma • Cassio Riccetto • Elaine Bronzatto • \\ Rodrigo Castro $\cdot$ Sebastian Altuna
}

Received: 15 May 2013 / Accepted: 26 September 2013 /Published online: 30 October 2013

(C) The Author(s) 2013. This article is published with open access at Springerlink.com

\begin{abstract}
Introduction and hypothesis The Ophira Mini Sling System involves anchoring a midurethral, low-tension tape to the obturator internus muscles bilaterally at the level of the tendinous arc. Success rates in different subsets of patients are still to be defined. This work aims to identify which factors influence the 2-year outcomes of this treatment.

Methods Analysis was based on data from a multicenter study. Endpoints for analysis included objective measurements: 1-h pad-weight (PWT), and cough stress test (CST), and questionnaires: International Consultation on Incontinence Questionnaire-Short Form (ICIQ-SF) and Urinary Distress Inventory (UDI)-6. A logistic regression analysis evaluated possible risk factors for failure.

Results In all, 124 female patients with stress urinary incontinence (SUI) underwent treatment with the Ophira procedure. All patients completed 1 year of follow-up, and 95 complied with the 2-year evaluation. Longitudinal analysis showed no significant differences between results at 1 and 2 years. The 2-year overall objective results were $81(85.3 \%)$ patients dry, six $(6.3 \%)$ improved, and eight $(8.4 \%)$
\end{abstract}

P. Palma $\cdot$ C. Riccetto $\cdot$ E. Bronzatto

Division of Female Urology, University of Campinas (UNICAMP),

Campinas, Brazil

R. Castro

Department of Gynecology, Federal University of São Paulo (UNIFESP), São Paulo, Brazil

\section{S. Altuna}

Department of Gynecology, Austral University Hospital, Buenos Aires, Argentina

C. Riccetto $(\bowtie)$

Rua Herman Muller, 429, Americana, SP, Brazil 13465-630

e-mail: cassioriccetto@gmail.com incontinent. A multivariate analysis revealed that previous anti-incontinence surgery was the only factor that significantly influenced surgical outcomes. Two years after treatment, women with previous failed surgeries had an odds ratio (OR) for treatment failure (based on PWT) of 4.0 [95\% confidence interval (CI) 1.02-15.57).

Conclusions The Ophira procedure is an effective option for SUI treatment, with durable good results. Previous surgeries were identified as the only significant risk factor, though previously operated patients showed an acceptable success rate.

Keywords Minisling $\cdot$ Ophira procedure $\cdot$ Single-incision sling $\cdot$ Stress urinary incontinence

\section{Introduction}

The understanding of stress urinary incontinence (SUI) pathophysiology has consistently improved over the past decade, resulting in the development of many surgical techniques. Based on the Integral Theory, Petros and Ulmsten proposed the tension-free vaginal tape (TVT). According to this theory, a midurethral tape can stabilize the urethra during straining without modifying urethral mobility [1, 2]. Ulmsten first introduced the TVT procedure for female SUI in 1995 [1], and it soon became known worldwide, with a reported cure rate of $>80 \%$ [2]. Despite this cure rate, major complications, such as injuries to the bowel and major blood vessels, have been described [3].

Palma introduced the Arc-to-Arc minisling as an alternative to the TVT procedure in 1999 [4]. In 2001, Delorme developed the transobturator tape (TOT) technique [5] to reduce perioperative complications related to the blind passage of 
needles in the retropubic space. Several studies reported high cure and low complication rates for TOT and, based on preoperative urodynamic findings and postoperative clinical examination, uroflowmetry, and cough test, the authors discussed the mechanisms responsible for the success of this treatment $[6,7]$. Continence rate with the transobturator approach is reportedly similar to that obtained with the transvaginal retropubic approach $[6,7]$. Most of the described complications of retropubic slings are related to the blind nature of these procedures [8].

The Ophira Mini Sling System is an innovative anatomical approach that involves anchoring a midurethral low-tension tape to the obturator internus muscles bilaterally at the level of the tendinous arc through a single vaginal incision. Its rationale is to reinforce the urethropelvic ligament with a transobturator tape. Although a recent publication has shown that minislings are as effective in nonobese as in obese patients, the ideal subset of patients for this procedure is still to be defined [9]. This study aimed to identify the most suited subset of patients for the Ophira procedure.

\section{Materials and methods}

An international, multicentric, prospective, open-label, singlearm, clinical study was carried out in two countries to assess the clinical performance of the Ophira Mini Sling System for treating female SUI. The local ethical committees approved the study, and all patients signed written informed consent. Only patients older than 18 years with clinical and urodynamic diagnosis of SUI and with absence of neurological disease and clinically significant detrusor overactivity were included. Exclusion criteria were urodynamic changes suggesting a reduction in bladder capacity; bladder compliance of or suggestive of bladder outlet obstruction; coagulopathies; pregnancy; history of sensitivity to foreign materials; acute urinary tract infection; acute vulvovaginitis; sequelae of exposure to ionizing radiation; use of drugs that can result in high surgical risk or risk of significant postoperative complications, including any drug that interferes with blood clotting; and contraindication to anesthetic procedure. Data were collected from 124 women, all of whom completed at least 1 year of follow-up; 95 (76.6\%) completed 2 years of follow-up. Workup included history, physical examination, stress test, standardized 1-h pad-weight test (PWT), and preoperative urodynamic study. Patients were also evaluated with two validated questionnaires: the International Consultation on Incontinence Questionnaire-Short Form (ICIQ-SF), and Urogenital Distress Inventory (UDI-6). During postoperative follow-up, patients were reviewed at 1, 3, 6, 12, and 24 months. For this analysis, 12- and 24-month data were compared to assess the durability of clinical outcomes. Objective cure of SUI (dry patients) was defined as urinary leakage $<1 \mathrm{~g}$ in the 1-h PWT [10], whereas improvement was defined as leakage $<50 \%$ of the preoperative value. Any greater urinary leakage was defined as treatment failure [11].

Single-incision minislings (SIMS) were used to treat SUI (Ophira Mini Sling System; Promedon, Córdoba, Argentina) composed of polypropylene monofilament mesh (type I) and relies on two self-anchoring polypropylene multipoint fixation arms for tissue fixation. A retractable insertion guide (RIG) is used to ensure accurate insertion. The RIG has two fixation points at its tip that act as an antirotational system (Fig. 1a-c).

The surgical procedure was generally carried out under local anesthesia, with $20 \mathrm{ml}$ of $2 \%$ lidocaine being injected at the midurethral point toward the vaginal fornix and advancing $2 \mathrm{~cm}$ into the obturator internus muscles. General or spinal anesthesia were less commonly used but were selected for some particular cases. A vertical, 2-cm vaginal incision was performed $1 \mathrm{~cm}$ from the urethral meatus. Minimal dissection was performed laterally toward the ascending ramus of the pubic bone, preserving the endopelvic fascia. Prior to implant insertion, a RIG was connected to a multipoint fixation arm. Guided by the surgeon's index finger, the guide was introduced behind the ascending ramus of the pubic bone toward the obturator internus muscle, $1 \mathrm{~cm}$ above the vaginal fornix. When the centering mark of the implant was underneath the urethra, the trigger on the handle was deployed to release the fixation arm and set it in place. The design of the multipoint fixation arm provides strong and stable primary fixation [12]. The same maneuvers were repeated on the other side. After fine adjustment of the mesh, the RIG was removed and the vaginal wall closed in the usual manner (Fig. 2). Cystoscopy was not mandatory but can be advised for patients with recurrent incontinence or based on the surgeon's intraoperative decision. No Foley catheters were left in place. Patients were discharged immediately after spontaneous voiding.

Statistical analyses were performed with SPSS ${ }^{\circledR} 17$ (Chicago, IL, USA). Continuous variables were compared with Student's independent $t$ test for transverse analysis and paired sample test for longitudinal analysis. Categorical variables were tested with the $X^{2}$ test for transverse analysis and the McNemar test when comparing pre- and postoperative values for the same subset of patients. Odds ratios (OR) for treatment failure at 2 years were also calculated. The main analysis was done to identify baseline factors that could predict surgical failure. For this purpose, an exploratory univariate analysis was performed, and posteriorly, a multivariate model was constructed (logistic regression), with variables of age, parity, body mass index (BMI), and Valsalva leak-point pressure (VLPP). A complementary longitudinal analysis was carried out to assess outcome stability over time. Data from the 1-and 2-year follow-ups were compared to fulfill this requirement. The level of statistical significance was fixed at $<0.05$ for all comparisons. 
Fig. 1 a-c Surgical set. Detail of Ophira Mini Sling System antirotational tip and retractable insertion guide
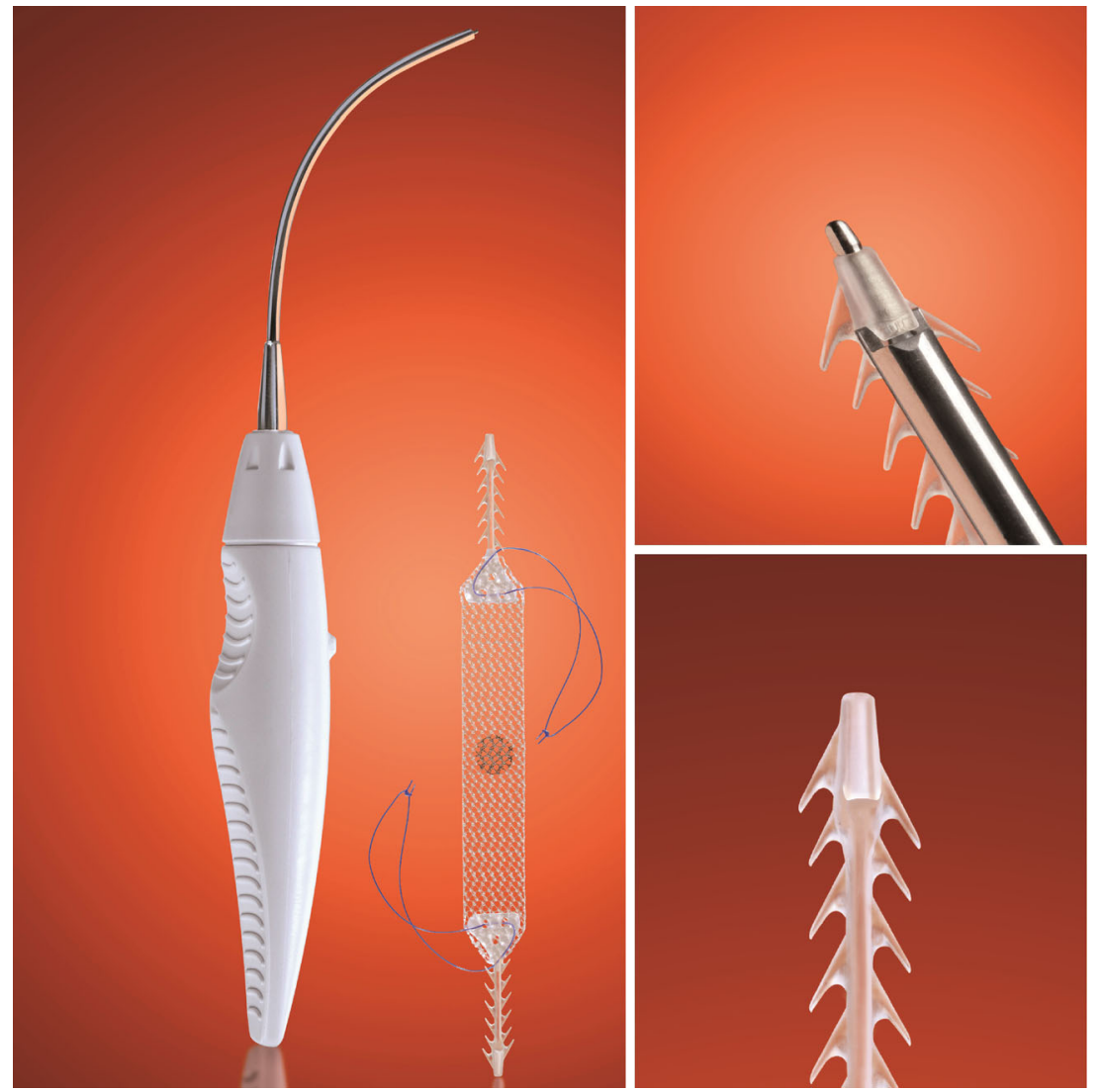

\section{Results}

One hundred and twenty-four patients completed 1 year of follow-up, and 95 complied with the 2-year follow-up evaluation. Relevant patient variables are shown in Table 1. Surgeries were done under local anesthesia in 90 (72.6 \%) cases. Mean [standard deviation (SD)] operative time was 17.0 (7.1) min.

Results from the longitudinal overall analyses are presented in Table 2. There were no significant differences between 1and 2-year follow-up data for mean PWT and CST or mean ICIQ-SF and UDI-6 scores.

To evaluate the effects of baseline factors on Ophira procedure outcomes, an exploratory univariate analysis was done prior to a logistic regression analysis, both summarized in Table 3. The numerical variables of age, parity, BMI, and VLPP were transformed in dichotomous variables for these analyses. The two categories for each new variable were as follows: age $\geq 60$ and $<60$ years, BMI $\geq 30$ and $<30 \mathrm{~kg} / \mathrm{m}^{2}$, parity $\geq 3$ and $<3$ gestations, and VLPP $\geq 60$ and $<60 \mathrm{cmH}_{2} \mathrm{O}$. Univariate analysis showed that only one factor was significantly associated with surgical failure: previous antiincontinence surgeries (OR 4.0, $p=0.032$ ). This finding was also confirmed after running a logistic regression model, where previous anti-incontinence surgeries remained the only variable significantly associated with surgical failure (OR 7.7, $p=0.04)$.
After the identification of previous surgeries as the only risk factor for surgical failure, the 2-year results were segmented according to this factor. Figure 3 depicted the percentages of cured, improved and failed cases within the following groups: overall results, naïve and previously operated patients. Table 4 showed the comparison of failure rates between those patients who received a previous antiincontinence surgery and those who did not. Naïve women achieved a significantly higher success rate than did patients who had previously undergone surgery according both to PWT and CST ( $p=0.032$ and $p=0.038$ respectively). On the other hand, there was not a statistically significant difference between these groups in UDI-6 scores. The mean (SD) UDI-6 score for the previously operated women was 2.5 (3.1) and for naïve patients 1.4 (1.6), $p=0.07$.

Within the operating room, three patients had symptoms of lidocaine hydrochloride overdose for which they were treated conservatively. One woman who underwent local anesthesia experienced severe intraoperative pain and needed intravenous sedation. There was no severe intraoperative bleeding or organ perforation (urethra, bladder, bowel, vessels). There was no infection, hematoma, or dyspareunia during follow-up. Sling exposure was observed in four patients $(3.2 \%$ ), all $<0.5 \mathrm{~cm}$ in diameter. Two of these patients were treated with local estrogen with good results and two by ambulatory resection. Four patients had urinary retention (3.2\%), which resolved 


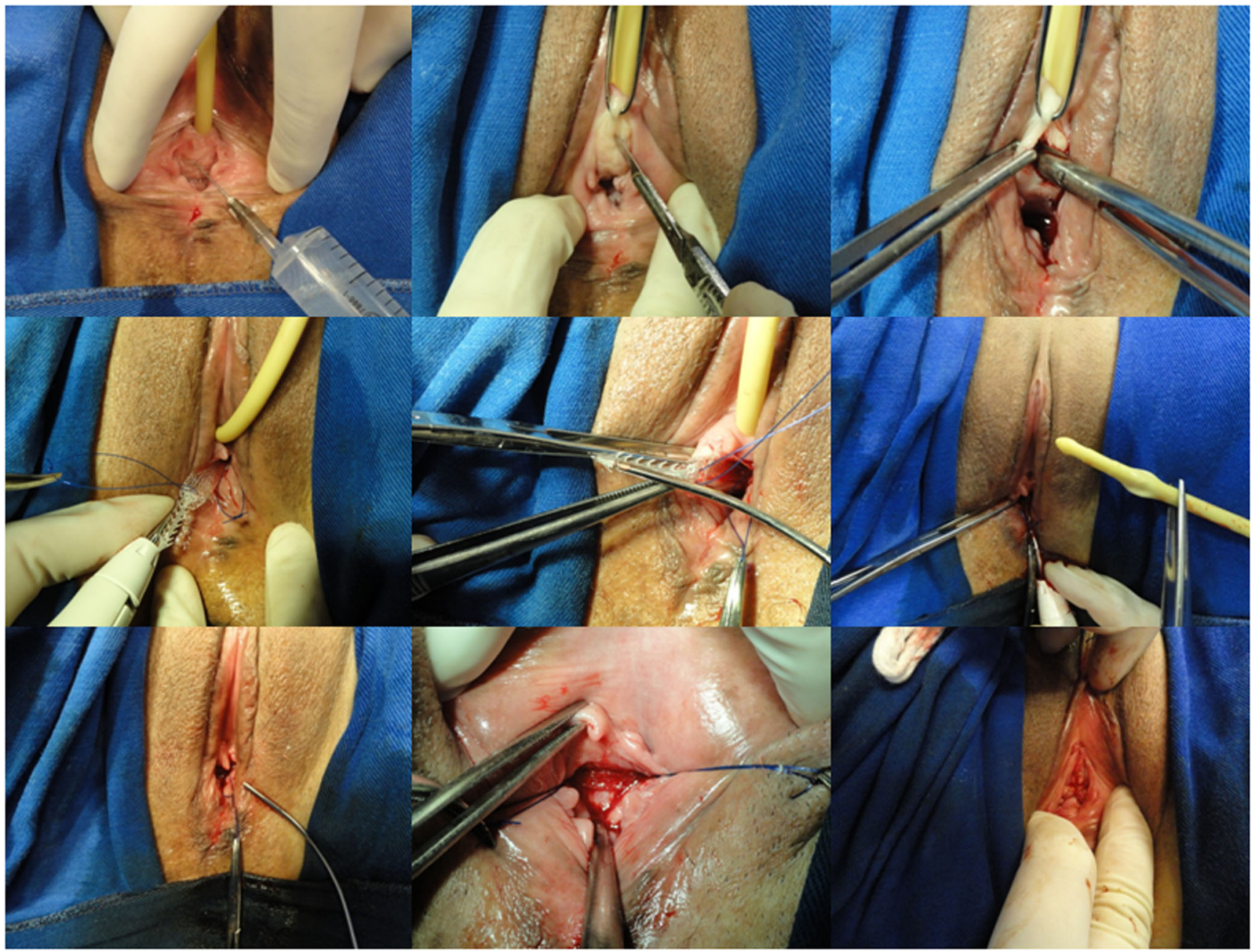

Fig. 2 a Local anesthesia; b vaginal incision; c dissection laterally toward the ascending ramus of the ischiopubic bone; $\mathbf{d}$, e mesh insertion; $\mathbf{f}$ intraoperative stress test; $\mathbf{g}$ removal of retractable insertion guide; $\mathbf{h}$ fine adjustment of the mesh; $\mathbf{i}$ end of the procedure

spontaneously in two and treated by mesh incision in one and by sling loosening in one. Nine patients $(7.3 \%)$ presented de novo urgency; all were treated initially with anticholinergics.

Table 1 Relevant baseline clinical variables for all participants $(n=124)$

\begin{tabular}{lc}
\hline Variables & Results \\
\hline Previous anti-incontinence surgeries, $n(\%)$ & $35(28.2)^{\mathrm{a}}$ \\
Age, mean (SD) [years] & $54.8(9.9)$ \\
Previous gestation, mean (SD) & $3.0(2.0)$ \\
Postmenopause, $n(\%)$ & $80(64.5)$ \\
VLPP, median (range) & $77.0(25.0-147.0)$ \\
Mixed urinary incontinence, $n(\%)$ & $51(41.1)$ \\
Body mass index, $\mathrm{kg} / \mathrm{cm}^{2}$, mean (SD) [] & $27.9(4.6)$ \\
\hline
\end{tabular}

\footnotetext{
${ }^{a}$ Twenty-eight of these patients reached 2-year follow-up. This is the number used for further analysis of naïve and previously operated patients
}

\section{Discussion}

Understanding physiopathological concepts of SUI has consistently improved over recent years, and treatment options have led to the development of many different surgical techniques. In the past decade, minimally invasive synthetic slings have replaced Burch colposuspension to become the preferred technique for treating SUI $[13,14]$. The driving aim of minislings is to reduce complications. In an attempt to reduce major problems, a new means of anatomical reconstruction of urethral support has been described; namely, the tissue fixation system. This reconstruction is achieved by bilaterally anchoring a low-tension suburethral tape to the obturator internus muscles at the level of the tendinous arc [8]. This procedure minimizes injuries to bowel and major vessels.

In our first study of the SIMS in 1999, we used bovine pericardium and obtained good initial results; however, there was an unacceptable rate of extrusion after 6 months [4]. This problem was later confirmed by a clinical trial using bovine 
Table 2 Comparison between objective and subjective 1- and 2-year follow-up outcomes

\begin{tabular}{|c|c|c|c|c|c|}
\hline Variables & & Preoperative $(n=124)$ & 1 year $(n=124)$ & 2 years $(n=95)$ & $P$ value (1 vs 2 years) \\
\hline \multirow[t]{4}{*}{ 1-h $\mathrm{PWT}^{\mathrm{a}, \mathrm{b}}$} & Mean (SD) & $12.5(15.4)$ & $1.4(5.9)$ & $2.2(9.1)$ & \multirow[t]{2}{*}{$0.477^{\mathrm{c}}$} \\
\hline & Dry, $n(\%)$ & NA & $103(83.1)$ & $81(85.3)$ & \\
\hline & Improvement, $n(\%)$ & NA & $9(7.3)$ & $6(6.3)$ & \multirow[t]{2}{*}{$0.368^{\mathrm{d}}$} \\
\hline & Failure, $n(\%)$ & NA & $12(9.7)$ & $8(8.4)$ & \\
\hline \multirow[t]{2}{*}{$\mathrm{CST}^{\mathrm{a}}$} & Negative, $n(\%)$ & $0(0)$ & $112(90.3)$ & $82(86.3)$ & \multirow[t]{2}{*}{$0.508^{d}$} \\
\hline & Positive, $n(\%)$ & $124(100)$ & $12(9.7)$ & $13(13.7)$ & \\
\hline ICIQ-SF $^{\mathrm{a}}$ & Mean (SD) & $15.8(3.9)$ & $3.0(5.1)$ & $1.9(4.3)$ & $0.148^{\mathrm{b}}$ \\
\hline UDI-6 ${ }^{\mathrm{a}}$ & Mean (SD) & $9.2(3.1)$ & $2.3(3.0)$ & $1.7(2.2)$ & $0.106^{\mathrm{b}}$ \\
\hline
\end{tabular}

PWT pad weight test, CST cough stress test, ICIQ-SF International Consultation on Incontinence Questionnaire-Short Form, UDI-6 Urinary Distress Inventory, $S D$ standard deviation

${ }^{a}$ Postoperative and preoperative records were compared using Student's two-tailed, dependent $t$ test for continuous variables and McNemar test for CST. All the comparisons resulted in $p<0.0005$

${ }^{\mathrm{b}}$ For the 1- and 2-year follow-ups, there were four and three missing data; we considered these as failed because the last failure was carried forward

${ }^{c}$ One- and 2-year comparison with Student's two-tailed independent $t$ test

${ }^{\mathrm{d}}$ One- and 2-year comparison with Student's independent $t$ test (PWT) and McNemar-Bowker test (CST)

pericardial slings in which a $90 \%$ rate of postoperative complications was reported [15]. Persisting with the principle of restoring the urethropelvic ligament, we reported the results of using porcine small-intestinal submucosa in 25 patients in 2001 [16]. The Arc-to-Arc mini sling using swine intestinal submucosa produced $60 \%$ good results in the long term (6 years' follow-up) [17]. In addition to the use of a single incision, other valuable advantages of this procedure are that it is generally performed under local anesthesia and is a quick and truly outpatient procedure.

A recently published meta-analysis compared SIMS with both retropubic and transobturator standard midurethral slings
(SMUS) [18]. It is important to mention that $71 \%$ of patients in the SIMS group received TVT Secur, the first SIMS commercially available, which has been associated with poor results. Moreover, a previous experimental study that highlighted the key importance of an effective primary fixation system for achieving good results with minislings showed that TVT Secur in particular is associated with delayed and less intense adherence to host tissue after implantation [12]. In subsequent studies, a later generation of SIMS showed substantially better results than TVT Secur. In these later series, the Ophira and Miniarc procedures produced comparable results [19-21].

Table 3 Univariate and multivariate analysis

\begin{tabular}{|c|c|c|c|c|c|}
\hline \multirow[t]{2}{*}{ Factor } & \multirow[t]{2}{*}{$\mathrm{N}_{\text {failed }} / \mathrm{N}_{\text {factor }}(\%)$} & \multicolumn{2}{|l|}{ Univariate analysis } & \multicolumn{2}{|c|}{ Multivariate analysis } \\
\hline & & OR $(95 \% \mathrm{CI})$ & $P$ value & OR $(95 \% \mathrm{CI})$ & $P$ value \\
\hline Previous surgery & $5 / 28(17.9)$ & $4.00(1.02-15.57)$ & $0.032 *$ & $7.7(1.1-53.6)$ & $0.04 *$ \\
\hline Age $\geq 60$ years & $3 / 31(9.7)$ & $1.26(0.32-4.85)$ & 0.759 & & \\
\hline VLPP $<60 \mathrm{cmH}_{2} \mathrm{O}$ & $4 / 30(13.3)$ & $4.31(0.74-25.04)$ & 0.081 & & \\
\hline $\mathrm{BMI} \geq 30 \mathrm{~kg} / \mathrm{m}^{2}$ & $4 / 25(16.0)$ & $2.81(0.64-12.25)$ & 0.156 & & \\
\hline Mixed incontinence & $2 / 29(6.9)$ & $0.74(0.14-3.91)$ & 0.723 & & \\
\hline Menopause & $6 / 53(10.2)$ & $1.83(0.35-9.62)$ & 0.468 & & \\
\hline Parity $\geq 3$ & $3 / 47(6.4)$ & $0.56(0.13-2.49)$ & 0.440 & & \\
\hline
\end{tabular}

$V L P P$ Valsalva leak-point pressure, $B M I$ body mass index, $O R$ odds ratio, $C I$ confidence interval

${ }^{\text {a }}$ Postoperative and preoperative records were compared using Student's two-tailed, dependent $t$ test for continuous variables and McNemar test for CST. All the comparisons resulted in $p<0.0005$

${ }^{\mathrm{b}}$ For the 1- and 2-year follow-ups, there were four and three missing data; we considered these as failed because the last failure was carried forward

${ }^{\mathrm{c}}$ One- and 2-year comparison with Student's two-tailed independent $t$ test

${ }^{\mathrm{d}}$ One- and 2-year comparison with Student's independent $t$ test (PWT) and McNemar-Bowker test (CST)

*Statistically significant 


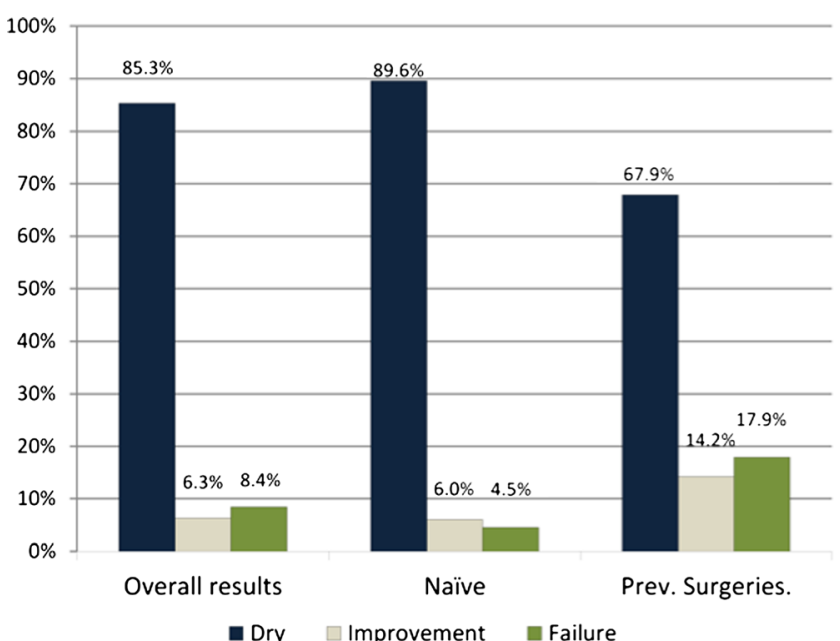

Fig. 3 Success rates according to pad weight test (PWT) for the segmented sample

However, the ideal patient for a minisling is still to be determined. To answer this question, we stratified patients as naïve, those who had previously undergone anti-incontinence procedures that had failed, and by age, setting the age of 60 years as the threshold. We obtained the best results in naïve patients $(89.6 \%$ cures). For elderly patients, the objective cure rate was $80.6 \%$, which resulted in a nonsignificant OR for failure of 2.0 (95\% 0.55-7.71). Although our results in the elderly are quite acceptable and not significantly different from those of younger patients, many studies have reported less than optimal results in the former subset of patients. In a previous study, the authors concluded that TVT in elderly patients ( $>70$ years) results in less favorable outcomes [22]. Because of low complication rates, bulking agents are frequently indicated for the elderly and patients who are unsuitable for surgery, even though they produce lower continence rates than SMUS [23]. The favorable results in elderly patients in our study indicate that this rationale (for bulking agent use) might also be considered for SIMS. Nevertheless, data from a randomized controlled trial are necessary to confirm or reject this possibility.

In clinical settings, the risk of failure must be related to safety. Many studies report an incidence of bladder perforation of $1-15 \%$ and an average perforation rate of $5 \%$ with a retropubic approach. On the other hand, transobturator slings have a lower rate of bladder and urethral injury during needle passage, which generally occurs in $<1 \%$ of patients, but this type of device usually causes groin pain. Bleeding, another important complication, occurs mainly during needle passage [13]. Bleeding upon entry into the retropubic space or the obturator internus muscles (in the transobturator route) can be difficult to manage. Moreover, some major complications, such as bowel and vascular injuries, as well as deaths have been reported [3]. Most of the described major complications are related to the blind nature of these procedures [8]. In this Ophira study, there were no cases of severe intraoperative bleeding, organ injury, or persistent pain. We consider that the absence of major complications in this series is attributable to reduction of the main risk factors; namely, reduction in blind passage of needles, the need for only one incision, and the relatively small extent of tissue dissection (considerably smaller than with SMUS).

For patients who had previously undergone surgery, the success rate was $67.9 \%$ and the OR for failure $4.0(95 \% \mathrm{CI}$ $1.02-15.57)$. In a prospective study of TVT in 34 women with recurrent SUI, the cure rate was $82 \%$ [22]. However, several studies using retropubic or transobturator slings failed to reproduce this high success rate for recurrent SUI, reporting cure rates ranging from $62 \%$ to $74 \%$ [24-27]. It is important to note that patients with good urethral mobility did better than those with fixed urethras.

To our knowledge, this is the first report of results of using minislings for recurrent SUI. Our results are similar to those reported for TVT or TOT in this subset of patients. Although our overall results are satisfactory, we stress that we achieved significantly better outcomes in the naïve group of patients.

In conclusion, the Ophira Mini Sling System is a safe and effective option for treating SUI and attans durable good results. The ideal candidates for this technique are naïve patients; previous surgeries were identified as the only significant risk factor, though previously operated patients showed an acceptable success rate.

Table 4 Results stratified according to the risk factor of previous anti-incontinence surgery

\begin{tabular}{|c|c|c|c|c|c|c|c|c|}
\hline \multirow[t]{2}{*}{ Variables $(n)$} & \multicolumn{2}{|c|}{ Failure according to PWT } & \multicolumn{2}{|c|}{ Positive CST } & \multicolumn{2}{|l|}{ ICIQ-SF } & \multicolumn{2}{|l|}{ UDI-6 } \\
\hline & $n(\%)$ & $P$ value $^{a}$ & $n(\%)$ & $P$ value ${ }^{a}$ & Mean (SD) & $P$ value ${ }^{b}$ & Mean (SD) & $P$ value ${ }^{b}$ \\
\hline Previous surgery (28) & $5(17.9)$ & $0.032 *$ & $7(25.0)$ & $0.038^{*}$ & $4.4(6.4)$ & $0.019^{*}$ & $2.5(3.1)$ & 0.070 \\
\hline Naïve patients (67) & $3(4.5)$ & & $6(9.0)$ & & $0.8(2.2)$ & & $1.4(1.6)$ & \\
\hline
\end{tabular}

${ }^{\mathrm{a}} \mathrm{X}^{2}$ test

${ }^{\mathrm{b}}$ Independent Student's $t$ test

*Statistically significant 
Financial disclaimer/Conflict of interest Palma P: Study support, consultant honorarium.

Riccetto C: None.

Bronzatto E: None.

Castro R: Study support.

Altuna S: Study support, consultant honorarium.

Open Access This article is distributed under the terms of the Creative Commons Attribution License which permits any use, distribution, and reproduction in any medium, provided the original author(s) and the source are credited.

\section{References}

1. Petros P, Ulmsten UI (1993) An integral theory and its method for the diagnosis and management of female urinary incontinence. Scand $\mathrm{J}$ Urol Nephrol 153:1-93

2. Ulmsten U, Henriksson L, Johnson P, Varhos G (1996) An ambulatory surgical procedure under local anesthesia for treatment of female urinary incontinence. Int Urogynecol J 7:81-86

3. Deng DY, Rutman M, Raz S, Rodriguez LV (2007) Presentation and management of major complications of midurethral slings: Are complications under-reported? Neurourol Urodyn 26:46-52

4. Palma PCR (1999) "Sling" tendineovaginal de pericárdio bovino. Experiência inicial. J Bras Ginecol 109:93-97

5. Delorme E (2001) La bandellette trans-obturatrice: un procede miniinvasif pour traiter l'incontinence urinaire d'effort de la femme. Prog Urol 1:1306-1313

6. Palma P, Riccetto C, Herrmann V, Dambros M, Thiel M, Bandiera S, Netto NR Jr (2005) Transobturator SAFYRE sling is as effective as the transvaginal procedure. Int Urogynecol J Pelvic Floor Dysfunct $16: 487-491$

7. Costantini E, Lazzeri M, Giannantoni A, Bini V, Vianello A, Kocjancic E, Porena M (2008) Preoperative Valsalva leak point pressure may not predict outcome of mid-urethral slings. Analysis from a randomized controlled trial of retropubic versus transobturator mid-urethral slings. Int Braz J Urol 34(1):73-81

8. Petros PE, Richardson P (2005) Midurethral tissue fixation system sling - a micromethod for cure of stress incontinence - preliminary report. Aust N Z J Obstet Gynaecol 45:372-375

9. Moore RD, De Ridder D, Kenelly MJ (2012) Two-year evaluation of the MiniArc in obese versus non-obese patients for treatment of stress urinary incontinence. Int J Urol. doi:10.1111/j.1442-2042.2012.03147.x

10. Tubaro, Artibani W, Bartram C et al (2009) Imaging and other investigations. In: Abrams P, Cardozo L, Khoury S, Wein A (eds) Incontinence, 4th edn. Health Publication Ltd, Paris, p 623

11. FDA Guidance Document (2011) Guidance for Industry and FDA Staff - Clinical Investigations of Devices Indicated for the Treatment of Urinary Incontinence. http://www.fda.gov/MedicalDevices/ DeviceRegulationandGuidance/GuidanceDocuments/ucm070852. htm. Accessed 14 Feb 2013.
12. Palma P, Siniscalchi RT, Maciel LC, Bigozzi MA, Dal Fabbro I, Riccetto C (2012) Primary fixation of mini slings: a comparative biomechanical study in vivo. Braz J Urol 38(2):253-260

13. Ogah J, Cody DJ, Rogerson L (2011) Minimally invasive synthetic suburethral sling operations for stress urinary incontinence in women: a short version Cochrane Review. Neurourol Urodyn 30: 284-291

14. Palma P (2007) A requiem to the Burch. Int Urogynecol J Pelvic Floor Dysfunct 18:589-590

15. Martucci RC, Ambrogini A, Calado AA, Zerati M, Muller MEA (2000) Pubovaginal sling with bovine pericardium for treatment of stress urinary incontinence. Braz J Urol 26:208-214

16. Palma PCR, Riccetto CLZ, Herrmann V, Dambros M, Mesquita R, Netto NR Jr (2001) Tendinous vaginal support (T.V.S.) using the porcine small intestine submucosa (SIS): a promising anatomical approach for urinary stress incontinence. J Urol 165:5 (A)

17. Palma P, Riccetto C, Fraga R, Martins M, Reges R, Oliveira M, Rodrigues Netto N Jr (2007) Long term follow- up of the tendinous urethral support: an anatomical approach for stress urinary incontinence. Actas Urol Esp 31:759-763

18. Fattah MA, Ford JA, Lim CP, Madhuvrata P (2011) Single-incision mini-slings versus standard midurethral slings in surgical management of female stress urinary incontinence: a meta-analysis of effectiveness and complications. Eur Urol 60(3):468-480

19. Palma PCR, Riccetto CLZ, Reges R, Fraga R, Myaoka R, Hermann V, Marcondes T (2008) Arcus to arcus microsling: technique and preliminary results. Int Urogynecol J 19:1133-1136

20. Hogewonin CRC, Ruhe IMC, Bekker MD, Hogewoning CJA, Putter H, DeRuiter MC, Pelge RCMR, Elzevier H W (2012). The MiniArc sling for female stress urinary incontinence: clinical results after 1-year follow-up. Int Urogynecol J Int Urogynecol J. 23(5):589-95, 18.

21. Moore RD, Mitchell GK, Miklos JR (2009) Single-center retrospective study of the technique, safety, and 12-month efficacy of the MiniArc ${ }^{\mathrm{TM}}$ single-incision sling: a new minimally invasive procedure for treatment of female SUI. Surg Technol Int 18:175-181

22. Rezapour M, Ulmsten U (2001) Tension-Free vaginal tape (TVT) in women with recurrent stress urinary incontinence-a long-term follow up. Int Urogynecol J Pelvic Floor Dysfunct 12(Suppl 2):S9-S11

23. Ghoniem GM, Miller CJ (2013) A systematic review and metaanalysis of Macroplastique for treating female stress urinary incontinence. Int Urogynecol J 24(1):27-36

24. Liapis A, Bakas P, Creatsas G (2009) Tension- free vaginal tape in the management of recurrent urodynamic stress incontinence after previous failed midurethral tape. Eur Urol 55:1450-1455

25. Meschia M, Pifarotti P, Gattei U, Bertozzi R (2007) Tension-free vaginal tape: analysis of risk factors for failures. Int Urogynecol $\mathrm{J}$ Pelvic Floor Dysfunct 18:419-422

26. Biggs GY, Ballert KN, Rosenblum N, Nitti V (2009) Patient-reported outcomes for tension-free vaginal tape-obturator women treated with a previous anti- incontinence procedure. Int Urogynecol J Pelvic Floor Dysfunct 20:331-335

27. Stav K, Dwyer PL, Rosamilia A, Schierlitz L, Lim YN, Chao F, De Souza A, Thomas E, Murray C, Conway C, Lee J (2010) Repeat synthetic mid urethral sling procedure for women with recurrent stress urinary incontinence. J Urol 183:241-246 